\title{
O enfermeiro novato na unidade de terapia intensiva: nexos com a segurança do paciente
}

\section{Newcomers nurses in the intensive care unit: linkages with the patient safety}

Patrícia Veras Neves de Oliveira' • Geilsa Soraia Cavalcanti Valente ${ }^{2}$

\section{RESUMO}

Este estudo teve como objetivo desenvolver uma reflexão sobre o enfermeiro novato na Unidade de Terapia Intensiva (UTI) e os possíveis nexos com a segurança do paciente. Trata-se de um artigo de reflexão e, para tal, foram realizadas leituras de artigos nos quais tratavam da admissão do enfermeiro na UTI. A partir dessas leituras, foram elencadas categorias que relacionavam a atuação deste enfermeiro na condição de novato na UTI à segurança do paciente, a saber: treinamento admissional; qualidade da assistência; autonomia e relações de trabalho; e experiência profissional. Conclui-se que há de uma estreita relação do enfermeiro novato na UTI à segurança do paciente e se faz necessário o desenvolvimento de estudos mais aprofundados relacionados a esta temática.

Palavras-chave:Admissão e escalonamento de pessoal; Educação em enfermagem; Unidades de terapia intensiva; Segurança do paciente.

\section{ABSTRACT}

This study had the objective of developing reflections about the nurses who are newcomers in the Intensive Care Unit (ICU) and the possible linkages with the patient' safety. It's a reflection article, so we performed readings of papers that addressed the admission of nurses in ICU. Based on these readings, we enumerated categories that related the performance of nurses in the condition of newcomers in ICU to the patient' safety, namely: admission training; quality of health care; autonomy and work relationships; and professional experience. We have concluded that there is a close relationship between the nurses who are newcomers in ICU and the patient safety, and that there is a need for the development of more in-depth studies related to this issue.

Keywords: Personnel staffing and scheduling; Education, Nursing; Intensive Care Units; Patient Safety.

${ }^{2}$ Enfermeira. PhD pela Escola Superior de Enfermagem do Porto/Portugal; Doutora em Enfermagem pela Escola de Enfermagem Anna Nery/UFRJ; Professora Adjunto III do Departamento de Fundamentos de Enfermagem e Administração da Escola de Enfermagem Aurora de Afonso Costa da Universidade Federal Fluminense/ UFF. Niterói-RJBrasil.E-mail: geilsavalente@yahoo.com.br 


\section{INTRODUÇÃO}

0 enfermeiro novato é aquele recém-admitido que desconhece as possíveis ferramentas num determinado contexto de trabalho ${ }^{1}$. Na Unidade de Terapia Intensiva (UTI), ele pode ingressar trazendo uma trajetória de cuidados exercida apenas na graduação, sendo esse seu primeiro campo de atuação fora da proteção acadêmica; ou aquele que traz uma experiência de cuidados ao paciente, sendo ou não no universo da UTI. Trata-se de um enfrentamento que exige reflexões e atitudes em direção a sua formação permanente diante da oportunidade de se especializar durante a prática. Entretanto, sabe-se que a UTI requer uma intensas vigilância e condutas por conta do perfil da gravidade dos pacientes e do arsenal tecnológico, podendo implicar questões de segurança do paciente, visto que, em meio a um despreparo profissional, podem ocorrer erros na assistência².

Com base nesta problemática, este estudo foi construído considerando os conceitos determinados no Programa Nacional de Segurança do Paciente (PNSP) ${ }^{3}$ que tem o intuito de reduzir a um mínimo aceitável os riscos de danos desnecessários, como também percebe a articulação da segurança do paciente à $\operatorname{RDC} n^{\circ} 7$, de 24/02/2010, que dispõe sobre os requisitos mínimos para funcionamento de Unidades de Terapia Intensiva ${ }^{4}$. Nesta proposta, o Programa Nacional de Educação Permanente em Saúde enfatiza que a Educação Permanente é a aprendizagem no cotidiano do trabalho considerando os problemas enfrentados na realidade, os conhecimentos e as experiências pessoais, tendo como objetivo transformar a prática e a organização do trabalho ${ }^{5}$. Por fim, a temática aqui abordada acata a Agenda Nacional de Prioridades de Pesquisa em Saúde do Ministério da Saúde no que tange a gestão do trabalho e educação em saúde 6 .

Esta reflexão também confere uma lacuna do conhecimento encontrada a partir de estudos que revelaram a escassez de pesquisas relacionadas à admissão do enfermeiro na UTT7,8, retratando também a escassez de pesquisas que relacionem essa admissão à segurança do paciente. Verte-se, então, como objetivo, refletir sobre o enfermeiro novato na UTI e os possíveis nexos com a segurança do paciente. Trata-se de um artigo de reflexão construído a partir de leituras realizadas em artigos voltados para a admissão do enfermeiro na UTI. Constatou-se a íntima relação dessa admissão às questões voltadas para segurança do paciente, sendo assim, foram elencadas categorias que relacionavam a atuação deste enfermeiro na condição de novato na UTI à segurança do paciente, a saber: treinamento admissional; qualidade da assistência; autonomia e relações de trabalho; e experiência profissional.

\section{TREINAMENTO ADMISSIONAL}

Sabe-se que o enfermeiro, ao ser admitido numa UTI, necessita ser apresentado ao novo contexto de trabalho.
Uma maneira de instrumentalizar este novato é através do treinamento admissional.Algumas instituições não possuem um treinamento admissional estruturado, porém isso é um risco que pode comprometer não apenas o profissional, mas o paciente e a instituição, visto que cada profissional admitido poderá traçar metas de aprimoramento voltadas exclusivamente à demanda do momento ou aos interesses pessoais, prejudicando na padronização da assistência e no perfil de trabalho da unidade9. Sendo assim, faz-se necessário que haja uma proposta de educação voltada para o treinamento admissional na UTI.

Neste sentido, como base para a construção do treinamento admissional na UTI, deve ser considerada a experiência que o novato traz, mesmo que este ainda não tenha experiência prévia em UTI. Contudo, acredita-se que a trajetória de vida, bem como a bagagem profissional e acadêmica, podem contribuir para a construção do aprendizado, devendo-se também considerar questões relacionais, éticas e comportamentais, bem como as dimensões técnico-científicas e as diretrizes institucionais ${ }^{10}$.

Entende-se que, dentro da educação permanente, o treinamento admissional deve ser implementado na busca da formação profissional, no âmbito institucional, e precisa ser planejado para ser eficaz e flexível à realidade local e ter avaliação de resultados e impactos. Ela é um componente essencial para gerenciar riscos na assistência em saúde e recomenda-se que haja uma política de educação que fomente o cuidado especializado ${ }^{4,9}$. No entanto, quando implementado, percebem-se falhas na formação acadêmica, implicando a ocorrência de incidentes ocasionados pelo enfermeiro novato, o que tem exigido esforços em adotar questões relacionadas ao ensino básico de enfermagem no seu planejamento de atividades, no intuito de minimizar riscos ao paciente ${ }^{8,11}$, buscando paralelamente o melhor desempenho e motivação profissional².

\section{QUALIDADE DA ASSISTÊNCIA}

A padronização no atendimento, inicialmente, é uma estratégia para manter a segurança do paciente, a qualidade assistencial, bem como a identidade da equipe profissional e da instituição ${ }^{12}$. Ela reflete na qualificação do processo de trabalho. À luz desse pensamento, coloca-se que há uma divergência entre a formação e qualidade da assistência prestada, ficando claro que, quanto menos formação, mais distante estará da qualidade assistencia ${ }^{13}$. Pondera-se que trabalhadores sem treinamento interferem na produção do resultado esperado, o que pode ser mensurado através dos indicadores de produtividade e de qualidade, como também nos índices de morbidade e mortalidade ${ }^{12}$.

Frequentemente, ocorrem esforços gerenciais em atingir padrões de qualidade no contexto da UTI, pois, ao perceberem falhas no cotidiano, instituem ou alteram a rotina. Entretanto, os padrões eficazes do cuidado devem ser investidos a começar do treinamento admissional dos enfermeiros, que precisa ser constantemente reavaliado 
e aprimorado, ou até, se for o caso, instituído, somando benefícios não apenas institucional como multiprofissional e consequentemente na qualidade da assistência.

\section{AUTONOMIA E RELAÇÕES DE TRABALHO}

A autonomia implica independência, pró-atividade, capacidade argumentativa, e está relacionada ao desenvolvimento de competências. 0 enfermeiro preceptor pode encorajar significativamente nesse sentido, estimulando o pensamento crítico e habilidades em situações que exijam condutas rápidas. Sabe-se, porém, que muitas vezes os preceptores necessitam se multiplicar em tarefas gerenciais, na assistência ao paciente e no ensino; isso tem sido referência de sobrecarga profissional prejudicando a segurança do paciente ${ }^{8-14}$.

Entretanto, pesquisas mostram que as relações interpessoais influenciam diretamente no aprendizado. Apoia-se que colegas de trabalho podem ser fonte de conhecimento disponível e útil ${ }^{15}$. Do contrário, evidenciase que essas relações, quando não sadias, aumentam o estresse da equipe, a carga de trabalho e a rotatividade de enfermeiros na UTI, o que ocasiona prejuízo na segurança do paciente ${ }^{10,14-16}$. As questões das relações transcende o saber fazer do profissional; é preciso saber viver junto ${ }^{17}$, é preciso produzir e trabalhar em equipe. Fazse necessário capacitar o profissional para as interações nas dimensões relacionais com o cliente, família e nas relações multiprofissionais, devendo superar conflitos de interesses ${ }^{7-13}$. Parte-se que a convivência permite uma formação cooperativa, uma reciprocidade rumo à aprendizagem significativa, "o aprendendo a aprender"17, visto que, no cuidado em saúde, o relacionamento humano deve ser considerado como fator preponderante.

\section{EXPERIÊNCIA PROFISSIONAL}

Discute-se sobre o ingresso de enfermeiros experientes ou não em assistência a pacientes graves em UTI ${ }^{12-18}$. Em contrapartida, frente à demanda de enfermeiros especialistas, a alta rotatividade de enfermeiros e aposentadorias, diversas UTIs têm suprido seu quadro de enfermeiros sem exigência prévia de especialização ${ }^{8-9}$. Entretanto, alguns estudos defendem que o enfermeiro especializado ou experiente em UTI pode beneficiar nos resultados ao paciente ${ }^{12-18}$, já o enfermeiro novato, além do impacto ao se deparar com o perfil dos paciente e da tecnologia encontrada na UTI, precisa aprender a gerenciar seu tempo, executar bem o trabalho, exercer a tomada de decisão e se socializar; ao passo que, quando se trata do enfermeiro recém-graduado, beneficia-se pela capacidade de aprendizagem ativa, ainda vindoura da graduação ${ }^{7}$.

No entanto, deve-se alertar que o novato com ou sem experiência em UTI envolve riscos, isto porque os conhecimentos e habilidades necessários para as situações complexas no novo contexto de trabalho estão em desenvolvimento ${ }^{8-10}$, somado aos confrontos com dilemas éticos e a tensão do ambiente que pode configurar no estresse profissional ${ }^{18}$. No que tange à segurança do paciente, apoia-se que o enfermeiro novato precisa exercer o trabalho de forma supervisionada até que se sinta seguro para realizar suas atividades com autonomia e qualidade. É importante que, desde a admissão do profissional e juntamente com a equipe de enfermagem, haja o reconhecimento da relação de segurança frente ao acolhimento do enfermeiro novato e o cenário assistencial de risco que caracteriza a UT/2-18.

\section{CONCLUSÃO}

Ao refletir sobre o enfermeiro novato na UTI e os nexos com a segurança do paciente, evidenciou-se que esta temática deve ser explorada com mais afinco, visto que a suscetibilidade do novato associada à vulnerabilidade do paciente grave podem gerar riscos. Houve o indício de que o treinamento admissional instrumentaliza o profissional, e suas bases de formação devem ser consideradas e aprimoradas para atender ao novo contexto de trabalho. Dessa mesma maneira, foi revelado que o enfermeiro novato deve ser direcionado a uma assistência comprometida com a qualidade do cuidado, compreendendo a dinâmica de trabalho e atuando no seu cotidiano sob uma prática crítica reflexiva, capacitando-o para as demandas e intercorrências que podem acontecer frente ao exercício profissional.

A autonomia profissional surge como uma característica peculiar do enfermeiro na UTI e ela é revelada na medida em que seu engajamento ao exercício profissional demonstra suas habilidades profissionais. No entanto, diante das várias competências do enfermeiro, deparase com o desafio das relações de trabalho, visto que, na condição de novato, cuidar, liderar e aprender a conviver; estipulando relações sadias; propicia essa formação para uma assistência segura ao paciente.

Foi identificado também que a necessidade de suprir as demandas de enfermeiros nas UTIs tem justificado a admissão de novatos sem experiência neste setor, o que não exime das questões de risco para o paciente nesta relação. No entanto, este profissional deve debutar neste novo contexto de trabalho de forma supervisionada, sempre considerando as possibilidades dos riscos que incidem.

Este estudo teve como limitação a escassez de pesquisas que tratassem especificamente do enfermeiro novato na UTI e sua relação com a segurança do paciente, outrossim, estudos paralelos puderam contribuir nesta construção. Acredita-se que esta iniciativa poderá subsidiar novos pesquisadores no aprofundamento desta temática, gerando novas reflexões e uma prática assistencial segura.

\section{REFERÊNCIAS}

1. Souza CJ, Valente GSC. Perfil do enfermeiro coordenador neófito no gerenciamento em unidade de terapia intensiva. 
Revista Enfermagem Profissional [Internet]. 2014 [acesso em 26 abr 2016]; 1 (2):521-32. Disponível em: http://www. seer.unirio.br/index.php/enfermagemprofissional/article/ view/3724

2. Mello JF, Barbosa SFF. Cultura de Segurança do Paciente em terapia intensiva: Recomendações da enfermagem. Texto contexto - enferm. [Internet]. 2013 Dez [acesso em $27 \mathrm{abr}$ 2016]; 22 (4): 1124-1133. Disponível em: http://dx.doi. org/10.1590/S0104-07072013000400031.

3. Ministério da Saúde (BR). Documento de referência para - Programa Nacional de Segurança do Paciente. Brasília: Ministério da Saúde [Internet]; 2014 [acesso em 27 abr 2016] Disponível em: http://bvsms.saude.gov.br/bvs/publicacoes/ documento_referencia_programa_nacional_seguranca.pdf

4. Ministério da Saúde (BR). Resolução n. 7 / de 24 de fevereiro de 2010: dispõe sobre os requisitos mínimos para funcionamento de Unidades de Terapia Intensiva e dá outras providências. Brasília [Internet]; 2010. [acesso em 27 abr 2016]. Disponível em: http://bvsms.saude.gov.br/bvs/saudelegis/anvisa/2010/ res0007_24_02_2010.html

5. Ministério da Saúde (BR). Política Nacional de Educação Permanente em Saúde. Brasília: Ministério da Saúde [Internet]; 2009. [acesso em 27 abr 2016] Disponível em: http://bvsms. saude.gov.br/bvs/publicacoes/politica_nacional_educacao_ permanente_saude.pdf

6. Ministério da Saúde (BR). Agência Nacional de Vigilância Sanitária. Agenda Nacional de Prioridades de Pesquisa em Vigilância Sanitária. Brasília: Agência Nacional de Vigilância Sanitária [Internet]; 2011 [acesso em 27 abr 2016]. Disponível em: http://portal.anvisa.gov.br/wps/ wcm/connect/3048f900474576208428d43fbc4c6735/ Prioridades_de_Pesquisa_em_Vigilancia_Sanitaria. pdf?MOD=AJPERES

7. Saghafi F, Hardy J, Hillege S. New graduate nurses' experiences of interactions in the critical care unit. Intensive Crit Care Nurs [Internet]. 2014 Jun;30(3):159-66. Disponível em: https:// www.ncbi.nlm.nih.gov/pubmed/23050568.

8. Kaddoura MA. The effect of preceptor beahavior on teh thinking skills of new graduate nurses in the Intensive care unit. J Contin Educ Nurs [Internet] 2013 Nov [acesso em 15 abr 2016]; 44 (11): 488-95. Disponível em: http://www.ncbi. $\mathrm{nlm}$.nih.gov/pubmed/23964674.

9. Lazzari DD, Schmidt N, Jung W. Educação continuada em unidade de terapia intensiva na percepção de enfermeiras. Rev. Enfermagem da UFSM [Internet] 2012 Jan/Abr [acesso em 18 abr 2016]; 2(1): 88-96. Disponível em: http://cascavel.ufsm.br/ revistas/ojs-2.2.2/index.php/reufsm/article/view/4592/3130

10. Bringsvor HB, Bentsen SB, Berland A. Sources of kmowlwdge used by Intensive care nurses in Norway: an exploratory study [Internet]. 2014 Jun; 3093:159-66. Disponível em: https:// www.ncbi.nlm.nih.gov/pubmed/24380660.

11. Rocha RM, Silvino ZR, Cortes ALB, Teixeira AF, Bomfim TCRS, Santana PPC. A relação das competências clínicas e profissional com o processo de trabalho em saúde. Rev In Derme Enferm Atual [Internet]. 2015 [acesso em 13 mai 2016]; 74(12):32-9. Disponível em: http://inderme.com.br/1205.html

12. Rodriguez KM. Intensivist training programs and standardization of care. Am J Crit Care [Internet]. 2012 Set [acesso em 15 abr 2016]; 21(5):308. Disponível em: http:// ajcc.aacnjournals.org/content/21/5/308.1.long. doi: 10.4037/ ajcc2012962

13. Baumann MH, Simpson SQ, Stahl M, Raoof S, Marciniuk DD, Gutterman DD et al. First, Do No Harm: Less Training \& Quality Care. Am J Crit Care [Internet] 2012 Jun [acesso em 18 abr 2016]; 21(4):227-30. Disponível em: http://ajcc. aacnjournals.org/content/21/4/227.full.

14. Tironi NM, Silva LGC, Dellaroza SMG, Haddad MCL, Vannuchi MTO. Repercussões gerenciais da rotatividade de pessoal sob a ótica de enfermeiros: pesquisa exploratória. Online Braz J Nurs [Internet] 2014 Dez [acesso em 25 abr 2016]; 13 (4): 549-58. Disponível em: http://dx.doi.org/10.5935/16764285.20144394

15. Peixoto LS, Tavares CMM, Daher DV. A relação interpessoal preceptor-educando sob o olhar de Maurice Tardif: reflexão teórica. Cogitare Enferm. [Internet] 2014 Jul/Set [acesso em 25 abr 2016]; 19(3):612-6. Disponível em: http://ojs.c3sl.ufpr. br/ojs2/index.php/cogitare/article/view/30468/23259

16. Padilha KG, Barbosa RL, Oliveira EM, Rafaela A, Ducci AJ, Secoli SR. Segurança do paciente em Unidades de Terapia Intensiva: desenvolvimento de um projeto de pesquisa. Rev. Esc Enferm USP [Internet] 2015 [acesso em 25 fev 2016]; 49(n. esp):157-63. Disponível em: http://www.scielo.br/pdf/ reeusp/v49nspe/1980-220X-reeusp-49-spe-0157.pdf.

17. Delors J. (Org.). Educação: um tesouro a descobrir: relatório para a UNESCO da Comissão Internacional sobre Educação para o século XXI. Brasília: UNESCO; 2010.

18. Mealer M, Conrad D, Evans J, Jooste K, Solyntjes J, Rothbaum $B$ et al. Feasibility and acceptability of a resilience training program for Intensive care unit nurses. Am J Crit Care [Internet]. 2014 Nov;23(6):e97-105. Disponível em: https:// www.ncbi.nlm.nih.gov/pubmed/25362680. 